\title{
Effect of Hydrogen Bonding on the Pyramidalization of the Amino Group: Structure of 3,4-diaminobenzamidinium Chloride
}

\author{
Ivana Stolić, ${ }^{a}$ Miroslav Bajić, ${ }^{a}$ and Dubravka Matković-Čalogović, ${ }^{\text {b,* }}$ \\ ${ }^{a}$ Department of Chemistry and Biochemistry, Faculty of Veterinary Medicine, University of Zagreb, Heinzelova 55, \\ HR-10000 Zagreb, Croatia \\ ${ }^{\mathrm{b}}$ Division of General and Inorganic Chemistry, Department of Chemistry, Faculty of Science, University of Zagreb, \\ Horvatovac 102a, HR-10000 Zagreb, Croatia
}

\begin{abstract}
. 3,4-diaminobenzamidinium was synthesized and spectroscopically and structurally characterized, both at room temperature and at $150 \mathrm{~K}$. The crystal structure consists of two 3,4diaminobenzamidinium cations and two chloride anions. The planar amidinium group is inclined by $35.35(5)^{\circ}$ and $28.96(7)^{\circ}$ in respect to the diaminobenzene moiety in the two crystallographically independent cations. The ions are interconnected by a large network of hydrogen bonds into a threedimensional structure. Pyramidalization of the amino group in relation to the hydrogen bond length in which the amino group is an acceptor is analized. Two amino groups are acceptors of $\mathrm{N}-\mathrm{H} \cdots \mathrm{N}$ hydrogen bonds of 2.9565(14) $\AA$ and 2.9654(15) $\AA$ resulting in pyramidalization of $340(1)^{\circ}$ and $337(1)^{\circ}$, respectively (the sum of the amino group bond angles is given as a measure of pyramidalization). A very weak hydrogen bond to one amino group results in a very flat pyramid $\left(351(1)^{\circ}\right)$, while one amino group is not acceptor of a hydrogen bonds and it is planar. The resonance effect has influence on the planar amino groups resulting in a shorter $\mathrm{C}-\mathrm{N}$ (amino group) bond length than in the pyramidalized ones. (doi: $10.5562 /$ cca2224)
\end{abstract}

Keywords: pyramidalization of the amino group, 3,4-diaminobenzamidinium chloride, X-ray single crystal structure analysis

\section{INTRODUCTION}

Natural products and synthetic organic cations that bind specifically and selectively to the DNA minor groove have therapeutic potential in a wide range of applications. ${ }^{1}$ The most studied DNA minor groove binders are aromatic amidines with cationic amidine moiety at terminal part of molecules. A large number of compounds from this class which comprise an amidino substituted benzimidazole ring show a potent antimicrobial, ${ }^{2-5}$ antivi$\mathrm{ral}^{6,7}$ and anticancer activity. ${ }^{8-10}$ The most convenient method of benzimidazole synthesis includes the condensation of 3,4-diaminobenzamidine with aldehyde in the presence of a suitable oxidative reagent such as: 1,4benzoquinone, ${ }^{10,11}$ sodium bisulfate,,${ }^{12,13}$ ceric ammonium nitrate ${ }^{14}$ or nitrobenzene. ${ }^{15}$ Synthesis and crystal structure determination of the title compound was of special interest in our search for a new bioactive compound.

Structure of 3,4-diaminobenzamidinium chloride shows a very interesting influence of hydrogen bonding on the pyramidalization of the amino group and de- serves a detailed analysis. Pyramidalization of the amino group is presented by the sum of two $\mathrm{C}-\mathrm{N}-\mathrm{H}$ angles and the $\mathrm{H}-\mathrm{N}-\mathrm{H}$ angle. Pyramidalization of the amino group was briefly discussed in the paper presenting the structure of hexaaminobenzene. ${ }^{16}$ It was noted that the $\mathrm{NH}_{2}$ groups were calculated to be more pyramidal (the three amino group bond angles are: $110.1^{\circ}, 110.1^{\circ}$, $\left.106.0^{\circ}\right)$ than the experimental values $\left(112(4)^{\circ}, 116(5)^{\circ}\right.$ and $\left.110(5)^{\circ}\right)$ and that this fact is not surprising considering the difficulty in assigning the hydrogen atom position in the crystal structure.

A very interesting analysis of the "tug-of-war" between pyramidalization and resonance in substituted anilines was published by Alabugin et al. ${ }^{17}$ It was calculated (B3LYP/6-31G and BLYP/6-311++G levels) that the non-planar conformation of aniline is $c a 1 \mathrm{kcal} / \mathrm{mol}$ more stable than the planar conformer. A detailed analysis of the influence of electron accepting and donating substituents in para and meta positions is also given. Their analysis of the crystal structures of substituted anilines deposited in the Cambridge Structural Data-

\footnotetext{
* Author to whom correspondence should be addressed. (E-mail: dubravka@chem.pmf.hr)
} 
base, $\mathrm{CSD}^{18}$ showed poor correlation between the computational data for the gas phase and the experimental data in the solid state. They concluded that such small differences in the energy of planar and pyramidalized anilines can be overruled by supramolecular forces that occur in the crystalline state.

In the crystal structures the pyramidalization is usually not much discussed because of problems in localizing the hydrogen atoms. A detailed analysis is made for the present structure showing how intermolecular contacts influence the degree of pyramidalization.

\section{EXPERIMENTAL}

\section{Synthesis of 4-amino-3-nitrobenzamidinium Chloride (1)}

A suspension of 4-amino-3-nitrobenzonitrile (1 g, 6.1 mmol) in dry dioxane $\left(15 \mathrm{~cm}^{3}\right)$ and dry methanol $(30$ $\mathrm{cm}^{3}$ ) was cooled to $0{ }^{\circ} \mathrm{C}$ and saturated with dry $\mathrm{HCl}(\mathrm{g})$. The flask was stoppered and the contents were stirred at room temperature until IR spectra indicated the disappearance of the nitrile peak (3 days). The suspension was cooled and diethyl-ether was added. The yellow solid was collected by filtration, washed with anhydrous diethyl-ether and dried over $\mathrm{KOH}$ to yield $1.17 \mathrm{~g} \mathrm{(83 \% )}$ of imido ester hydrochloride. Absolute ethanol saturated with ammonia $\left(50 \mathrm{~cm}^{3}\right)$ was added to the suspension of crude imido ester hydrochloride (1.17 $\mathrm{g}, 5 \mathrm{mmol})$ in absolute ethanol $\left(20 \mathrm{~cm}^{3}\right)$ and the mixture was heated at $50{ }^{\circ} \mathrm{C}$ for $3 \mathrm{~h}$, and then stirred over night at room temperature. Solvent was reduced under reduced pressure, and anhydrous ether was added. The formed solid was filtered off and washed with anhydrous ether to yield 4amino-3-nitrobenzamidinium chloride as an orange solid: $0.56 \mathrm{~g}(51 \%)$, m.p. $>300^{\circ} \mathrm{C}$; IR(KBr) $\tilde{v}_{\max } / \mathrm{cm}^{-1}$ : 3454, 3422, 3136, 1690, 1629, 1501, 1364, 1262, 1185, 1093, 910, 676; ${ }^{1} \mathrm{H}$ NMR (300 MHz, DMSO-d $) \delta /$ ppm: 9.13 (br s, $4 \mathrm{H}, \mathrm{NH}_{2}$ ), $8.63(\mathrm{~d}, 1 \mathrm{H}, J=2.30 \mathrm{~Hz}$, ArH), 8.12 (br s, 2H, NH 2$), 7.84\left(\mathrm{dd}, 1 \mathrm{H}, J_{\mathrm{A}}=9.05 \mathrm{~Hz}\right.$, $\left.J_{\mathrm{B}}=2.31 \mathrm{~Hz}, \mathrm{ArH}\right), 7.17(\mathrm{~d}, 1 \mathrm{H}, J=9.05 \mathrm{~Hz}, \mathrm{ArH}) ;{ }^{13} \mathrm{C}$

Table 1. General and crystal data and summary of intensity data collection and structure refinement of 2

\begin{tabular}{|c|c|c|}
\hline Formula & \multicolumn{2}{|c|}{$\left(\mathrm{C}_{7} \mathrm{H}_{11} \mathrm{~N}_{4}\right)^{+} \mathrm{Cl}^{-}$} \\
\hline$M_{\mathrm{r}}$ & \multicolumn{2}{|c|}{186.65} \\
\hline Crystal dimension $/ \mathrm{mm}^{3}$ & $0.47 \times 0.20 \times 0.14$ & $0.15 \times 0.22 \times 0.12$ \\
\hline Crystal system, space group & Monoclinic, $P 2{ }_{1} / c$ & \\
\hline$a / \AA$ & $11.6075(5)$ & $11.57746(14)$ \\
\hline$b / \AA$ & $9.8253(4)$ & $9.72729(12)$ \\
\hline$c / \AA$ & $16.4872(7)$ & $16.4185(2)$ \\
\hline$\beta /{ }^{\circ}$ & $104.507(4)$ & $104.7365(13)$ \\
\hline$V / \AA^{3}$ & $1820.37(13)$ & $1788.19(4)$ \\
\hline$Z$ & 8 & 8 \\
\hline$D_{\mathrm{c}} / \mathrm{g} \mathrm{cm}^{-3}$ & 1.362 & 1.387 \\
\hline$\mu / \mathrm{mm}^{-1}$ & 0.371 & 0.377 \\
\hline Temperature / K & $295(2)$ & $150(2)$ \\
\hline $2 \theta$ range for data collection $/{ }^{\circ}$ & $4.3-28.5$ & $4.3-29.0$ \\
\hline$h, k, l$ range & -15 to $15,-13$ to $13,-21$ to 22 & -15 to $15,-13$ to $13,-22$ to 22 \\
\hline No. measured reflections & 15312 & 29968 \\
\hline No. independent reflections $\left(R_{\text {int }}\right)$ & $4580(0.034)$ & $4730(0.024)$ \\
\hline No. refined parameters & 281 & 281 \\
\hline No. observed reflections, $I \geq 2 \sigma(I)$ & 2930 & 4280 \\
\hline$R^{(\mathrm{a})}, w R^{(\mathrm{b})}[I \geq 2 \sigma(I)]$ & $0.0339,0.0770$ & $0.0305,0.0832$ \\
\hline$R, w R$ [all data] & $0.0612,0.0723$ & $0.0349,0.0863$ \\
\hline Goodness of fit on $F^{2}, S^{(c)}$ & 0.86 & 1.009 \\
\hline$g_{1}, g_{2}$ in $w^{(\mathrm{d})}$ & $0.0413,0$ & $0.0523,0.5072$ \\
\hline Max., min. electron density / e $\AA^{-3}$ & $0.257,-0.162$ & $0.367,-0.205$ \\
\hline Maximum $\Delta / \sigma$ & 0.001 & 0.001 \\
\hline
\end{tabular}


NMR (150.9 MHz, DMSO-d 6 ) $\delta$ / ppm: 163.47, 149.04, $133.58,129.67,127.53,119.42,113.34$.

\section{Synthesis of 3,4-diaminobenzamidinium Chloride (2)}

A solution of 4-amino-3-nitrobenzamidinium chloride $(0.558 \mathrm{~g}, 2.6 \mathrm{mmole})$ in methanol $\left(30 \mathrm{~cm}^{3}\right)$ and $0.3 \mathrm{~g}$ of $10 \% \mathrm{Pd}-\mathrm{C}$ was hydrogenated at room temperature for 5 $\mathrm{h}$. The catalyst was removed by filtration and the solvent was removed under reduced pressure. The resultant solid was dissolved in ethanol saturated with dry $\mathrm{HCl}$ gas and diethyl-ether was added. The formed pale brown solid was collected by filtration and dried to yield 3,4diaminobenzamidinium chloride: $0.3 \mathrm{~g}$ (61.5 \%), m.p. 242-245 ${ }^{\circ} \mathrm{C}$ (lit.1 237-239 ${ }^{\circ} \mathrm{C}$ ); IR(KBr) $\tilde{\mathrm{v}}_{\max } / \mathrm{cm}^{-1}$ : $3467,3210,1643,1481,1316,1164,939,885,736 ;{ }^{1} \mathrm{H}$ NMR (300 MHz, DMSO-d $\left.{ }_{6}\right) \delta /$ ppm: 8.73 (s, 2H, NH N $_{2}$, $8.52\left(\mathrm{~s}, 2 \mathrm{H}, \mathrm{NH}_{2}\right), 6.99\left(\mathrm{dd}, 1 \mathrm{H}, J_{\mathrm{A}}=8.21 \mathrm{~Hz}, J_{\mathrm{B}}=2.12\right.$ $\mathrm{Hz}, \mathrm{ArH}), 6.93$ (d, 1H, $J=2.09 \mathrm{~Hz}, \mathrm{ArH}), 6.59$ (d, 1H, $J$ $=8.19 \mathrm{~Hz}, \mathrm{ArH}$ ), 5.60 (br s, 2H, $\mathrm{NH}_{2}$ ), 5.00 (br s, 2H, $\left.\mathrm{NH}_{2}\right) ;{ }^{13} \mathrm{C}$ NMR $\left(75 \mathrm{MHz}, \mathrm{DMSO}-\mathrm{d}_{6}\right) \delta / \mathrm{ppm}: 165.87$, 142.10, 134.34, 119.34, 114.59, 113.23, 113.07.

\section{IR Spectroscopy}

The single reflection attenuated total reflection (SRATR) FT-IR spectra were recorded at a resolution of 4 $\mathrm{cm}^{-1}$ on an ABB Bomem MB102 single beam FT-IR spectrometer, equipped with CsI optics and a DTGS detector. The spectra were recorded with a total of 30 scans using a horizontal single-reflection ATR diamond prism with $45^{\circ}$ angle of incidence. Each spectrum was recorded as the ratio of the sample spectrum to the spectrum of the empty ATR plate.

\section{X-ray Structural Analysis of 2}

Recrystallization from methanol resulted in crystals of good quality for X-ray diffraction only for 2 . The single-crystal X-ray diffraction data of 2 were collected by $\omega$-scans on an Oxford Diffraction Xcalibur 3 CCD diffractometer. Data reduction that included an empirical absorption correction using spherical harmonics was performed using the CrysAlisPro software package. ${ }^{19}$ The structure was solved by direct methods using SHELXS. $^{20}$ The refinement procedure was performed by the full-matrix least-squares method based on $F^{2}$ against all reflections using SHELXL. ${ }^{20}$ The nonhydrogen atoms were refined anisotropically. Graphitemonochromated Mo- $K_{\alpha}$ radiation $(\lambda=0.71073 \AA)$ was used for data collections both at room temperature and at $150 \mathrm{~K}$. Details of data collection and crystal structure refinement are given in Table 1.

All $\mathrm{H}$ atoms were first located in a difference Fourier map. The $\mathrm{N}$-bound $\mathrm{H}$ atoms were freely refined. Those bound to $\mathrm{C}$ atoms were refined as riding with $U_{\text {iso }}(\mathrm{H})=$ $1.2 U_{\text {eq }}(\mathrm{C})$ and $\mathrm{C}-\mathrm{H}$ distance of $0.93 \AA$ or $0.95 \AA$ for the

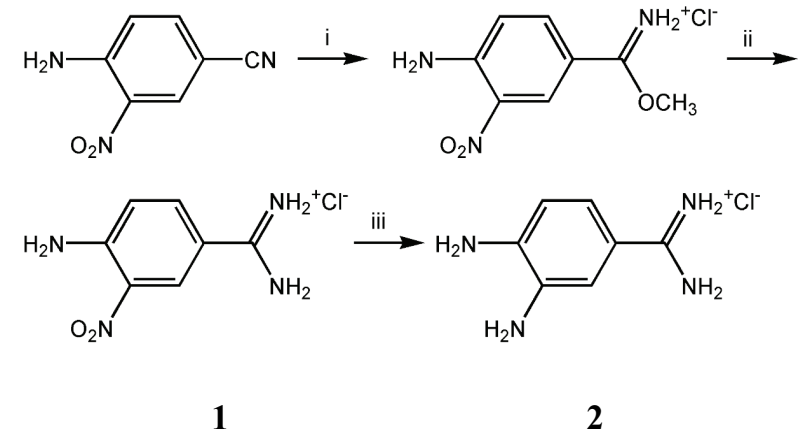

Scheme 1. Reagents: i) $1 . \mathrm{HCl}, \mathrm{MeOH}$, dioxane; ii) $\mathrm{NH}_{3}$; iii) $\mathrm{H}_{2}-10 \% \mathrm{Pd} / \mathrm{C}, \mathrm{MeOH}$.

room and low temperature structures, respectively. The geometrical calculations and molecular graphics were done with PLATON98 ${ }^{21}$ and Mercury 3.0. ${ }^{22}$

\section{RESULTS AND DISCUSSION}

Compound 2 was prepared from 4-amino-3-nitrobenzonitrile by the method described earlier for 3,4-diaminobenzamidine $^{23}$ (Scheme 1) however no spectroscopic data of compound $\mathbf{1}$ or $\mathbf{2}$ was published in the literature.

\section{IR spectroscopy}

The molecule of $\mathbf{1}$ contains three groups that are capable of forming hydrogen bonds: amino group, nitro group and amidino whereas that of $\mathbf{2}$ has only the amino and amidino groups. The spectral region above $3000 \mathrm{~cm}^{-1}$ is the most useful one for the detection and interpretation of H-bonds in these compounds.

The strong sharp IR signal around $3400 \mathrm{~cm}^{-1}$ indicates $\mathrm{N}-\mathrm{H}$ stretching of the free amino groups. There are two such signals in the IR spectrum of compound $\mathbf{1}$. The IR spectrum indicates that a significant number of amino groups of the amidino moieties are sterically hindered and thus are not forming hydrogen bonds. There is also a broad signal in the range of 3100-3300 $\mathrm{cm}^{-1}$ which indicates $\mathrm{N}-\mathrm{H}$ stretching of the associated amino groups. In the IR spectrum of the amino derivative 2 only signals belonging to the associated amino groups are present. A wide signal around 3100-3300 $\mathrm{cm}^{-1}$ is associated with $\mathrm{N}-\mathrm{H}$ stretching of hydrogen bonded amino groups which is in agreement with the crystal structure.

\section{Crystal Structure of 3,4-diaminobenzamidinium Chloride (2)}

The asymmetric unit consists of two 3,4-diaminobenzamidinium cations and two chloride anions (Figure 1). All interatomic distances in this discussion refer to the structure at $150 \mathrm{~K}$, however the tables include values 


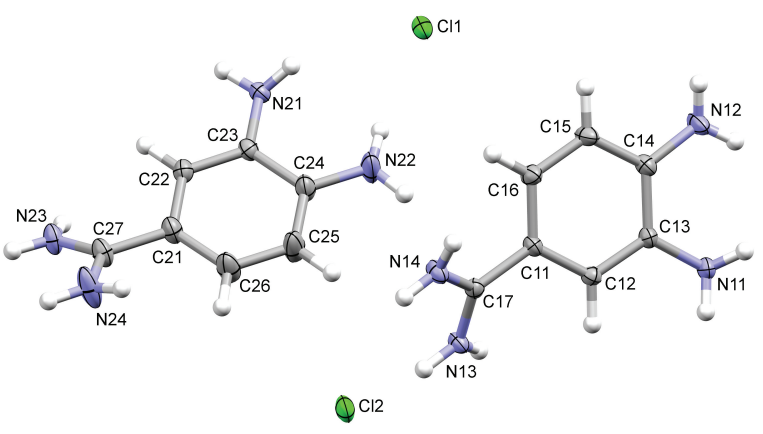

Figure 1. The asymmetric unit of 3,4-diaminobenzamidinium chloride (2) at $150 \mathrm{~K}$ with displacement ellipsoids drawn at the $50 \%$ probability level. Hydrogen atoms are drawn as small circles of arbitrary radius.

for both room and low temperature structures. The molecules are not planar, the amidinium group is inclined by $35.35(5)^{\circ}$ and $28.96(7)^{\circ}$ in respect to the diaminobenzene moiety in the two crystallographically independent cations ( $\mathrm{H}$ atoms were not included in the plane calculations). A slightly greater inclination was found in the structure of benzamidinium chloride monohydrate

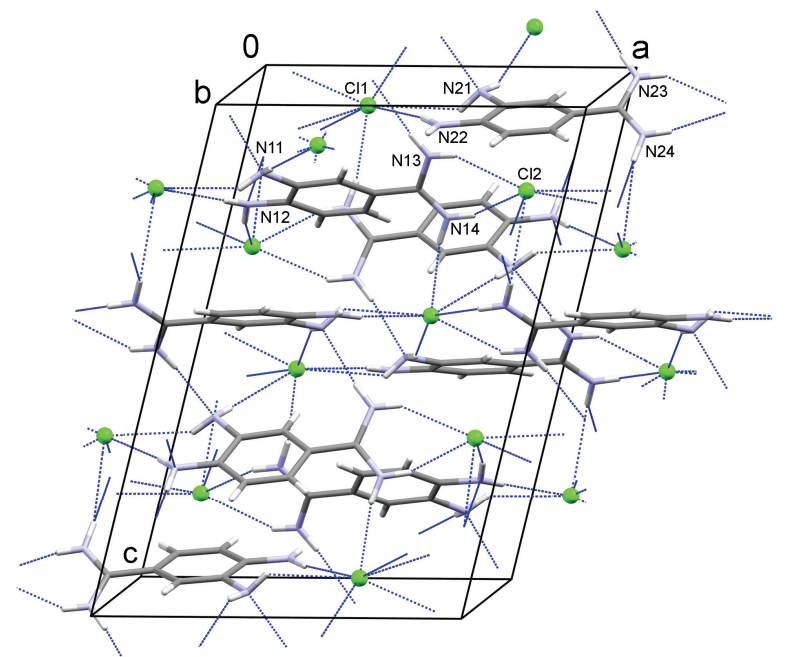

Figure 2. Packing of 3,4-diaminobenzamidinium chloride (2) in the unit cell. Hydrogen bonds are shown by blue dotted lines.

$\left(36.6(8)^{\circ}\right)^{24}$ or 1,3-benzothiazole-6-carboxamidinium chloride dihydrate, $36.71(9)^{\circ}{ }^{25}$

The ions are interconnected by a large network of hydrogen bonds in all three dimensions (Figure 2, Table 2).

Table 2. General and crystal data and summary of intensity data collection and structure refinement of 2

\begin{tabular}{|c|c|c|c|c|}
\hline $\mathrm{D}-\mathrm{H} \cdots \mathrm{A}$ & D-H & $\mathrm{H} \cdots \mathrm{A}$ & $\mathrm{D} \cdots \mathrm{A}$ & $\mathrm{D}-\mathrm{H} \cdots \mathrm{A}$ \\
\hline \multirow{2}{*}{$\mathrm{N} 11-\mathrm{H} 11 \mathrm{~A} \cdots \mathrm{Cl1}{ }^{(\mathrm{i})}$} & $0.80(2)$ & $2.81(2)$ & $3.5862(15)$ & $163.3(14)$ \\
\hline & $0.85(2)$ & $2.74(2)$ & $3.5620(10)$ & $162.9(14)$ \\
\hline \multirow{2}{*}{$\mathrm{N} 11-\mathrm{H} 11 \mathrm{~B} \cdots \mathrm{Cl} 2^{(\mathrm{ii})}$} & $0.85(2)$ & $2.76(2)$ & $3.4600(15)$ & $141.4(14)$ \\
\hline & $0.85(2)$ & $2.73(2)$ & $3.4399(10)$ & $141.0(14)$ \\
\hline \multirow{2}{*}{$\mathrm{N} 12-\mathrm{H} 12 \mathrm{~A} \cdots \mathrm{Cl} 2^{(\mathrm{ii})}$} & $0.84(2)$ & $2.48(2)$ & $3.3137(17)$ & $169.3(16)$ \\
\hline & $0.81(2)$ & $2.50(2)$ & $3.2988(11)$ & $168.2(18)$ \\
\hline \multirow{2}{*}{$\mathrm{N} 12-\mathrm{H} 12 \mathrm{~B} \cdots \mathrm{Cl} 2^{\text {(iii) }}$} & $0.84(2)$ & $2.56(2)$ & $3.3578(17)$ & $157.2(14)$ \\
\hline & $0.85(2)$ & $2.53(2)$ & $3.3335(12)$ & $157.3(16)$ \\
\hline \multirow{2}{*}{$\mathrm{N} 13-\mathrm{H} 13 \mathrm{~A} \cdots \mathrm{Cl} 2$} & $0.81(2)$ & $2.58(2)$ & $3.3127(16)$ & $151.8(13)$ \\
\hline & $0.88(2)$ & $2.51(2)$ & $3.2894(11)$ & $147.7(14)$ \\
\hline \multirow{2}{*}{$\mathrm{N} 13-\mathrm{H} 13 \mathrm{~B} \cdots \mathrm{N} 21^{(\mathrm{iv})}$} & $0.85(2)$ & $2.13(2)$ & $2.969(2)$ & $173.4(15)$ \\
\hline & $0.85(2)$ & $2.12(2)$ & $2.9565(14)$ & $173.5(16)$ \\
\hline \multirow{2}{*}{$\mathrm{N} 14-\mathrm{H} 14 \mathrm{~A} \cdots \mathrm{Cl} 1^{(\mathrm{v})}$} & $0.86(2)$ & $2.39(2)$ & $3.2336(15)$ & $165.7(14)$ \\
\hline & $0.85(2)$ & $2.27(2)$ & $3.2137(10)$ & $169.1(15)$ \\
\hline \multirow{2}{*}{ N14-H14B $\cdots \mathrm{Cl} 2$} & $0.85(2)$ & $2.45(2)$ & $3.2514(16)$ & $155.7(14)$ \\
\hline & $0.85(2)$ & $2.47(2)$ & $3.2444(10)$ & $152.8(14)$ \\
\hline \multirow{2}{*}{$\mathrm{N} 21-\mathrm{H} 21 \mathrm{~A} \cdots \mathrm{Cl} 1$} & $0.85(2)$ & $2.88(2)$ & $3.5085(15)$ & $132.2(13)$ \\
\hline & $0.84(2)$ & $2.85(2)$ & $3.4995(10)$ & $135.2(14)$ \\
\hline \multirow{2}{*}{$\mathrm{N} 21-\mathrm{H} 21 \mathrm{~B} \cdots \mathrm{Cl1}{ }^{(\mathrm{vi})}$} & $0.84(2)$ & $2.80(2)$ & $3.5745(15)$ & $153.3(15)$ \\
\hline & $0.86(2)$ & $2.74(2)$ & $3.5523(10)$ & $157.7(14)$ \\
\hline \multirow{2}{*}{ N22-H22B $\cdots \mathrm{Cl} 1$} & $0.84(2)$ & $2.58(2)$ & $3.411(2)$ & $170.6(16)$ \\
\hline & $0.87(2)$ & $2.51(2)$ & $3.3739(13)$ & $172.7(17)$ \\
\hline \multirow{2}{*}{$\mathrm{N} 23-\mathrm{H} 23 \mathrm{~A} \cdots \mathrm{N} 11^{\text {(iv) }}$} & $0.86(2)$ & $2.13(2)$ & $2.982(2)$ & $173.5(16)$ \\
\hline & $0.88(2)$ & $2.09(2)$ & $2.9654(15)$ & $171.0(15)$ \\
\hline \multirow{2}{*}{$\mathrm{N} 23-\mathrm{H} 23 \mathrm{~B} \cdots \mathrm{Cl1}{ }^{(\mathrm{vii})}$} & $0.80(2)$ & $2.55(2)$ & $3.2704(17)$ & $150.9(14)$ \\
\hline & $0.84(2)$ & $2.49(2)$ & $3.2460(11)$ & $149.8(16)$ \\
\hline \multirow{2}{*}{$\mathrm{N} 24-\mathrm{H} 24 \mathrm{~A} \cdots \mathrm{Cl} 1^{\text {(vii) }}$} & $0.80(2)$ & $2.77(2)$ & $3.406(2)$ & $138.0(16)$ \\
\hline & $0.86(2)$ & $2.70(2)$ & $3.4178(14)$ & $141.7(16)$ \\
\hline \multirow[t]{2}{*}{$\mathrm{N} 24-\mathrm{H} 24 \mathrm{~B} \cdots \mathrm{N} 12^{(\text {viii) }}$} & $0.87(2)$ & $2.67(2)$ & $3.419(2)$ & $144.7(19)$ \\
\hline & $0.89(2)$ & $2.52(2)$ & $3.3135(14)$ & $148.9(18)$ \\
\hline
\end{tabular}

Symmetry codes: (i) $x, y+1, z$; (ii) $x-1, y, z$; (iii) $-x+1, y-1 / 2,-z+1 / 2$; (iv) $-x+1,-y+1,-z$; (v) $-x+1, y+1 / 2,-z+1 / 2$; (vi) $-x+1,-y,-z$; (vii) $x+1, y, z$; (viii) $-x+2, y-1 / 2,-z+1 / 2$. 


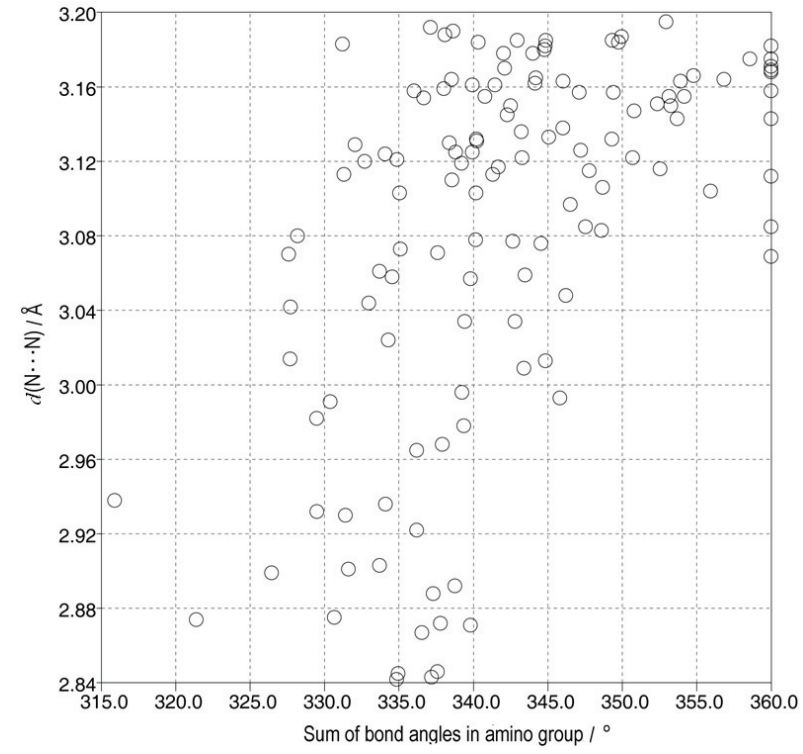

Figure 3. Scatter plot of 127 hits from the CSD illustrating the relation of the sum of the bond angles in the amino group and the $\mathrm{N} \cdots \mathrm{N}$ distance in the $\mathrm{N}-\mathrm{H} \cdots \mathrm{N}$ (amino group) hydrogen bond.

The two chloride ions are hydrogen bond acceptors of seven $(\mathrm{Cl} 1)$ or six (Cl2) hydrogen bonds. The amidinium groups are hydrogen bond donors while the amino groups are donors and acceptors resulting in a different degree of pyramidalization of the amino groups. We believe that the present structure is adequate for such analysis since all hydrogen atoms were found in the difference Fourier map and those $\mathrm{N}$ bound were isotropically refined. Also, there was no great variation in the $\mathrm{N}-\mathrm{H}$ bond lengths. The amidinium groups are planar with insignificant differences in the two $\mathrm{C}-\mathrm{N}$ bond lengths within the same group indicating electron delocalization.

We analyzed interactions involving the four amino groups in the two independent molecules all of which form hydrogen bonds. All are hydrogen bond donors toward the chloride ions, three of them have both hydrogen atoms involved in the $\mathrm{N}-\mathrm{H} \cdots \mathrm{Cl}$ hydrogen bonding while N22 has only one. The intermolecular interactions which we believe are crucial for pyramidalization of the amino group in these molecules are hydrogen bonds in which the amino groups are acceptors. Three amino groups are acceptors of $\mathrm{N}-\mathrm{H} \cdots \mathrm{N}$ hydrogen bonds

Table 3. Pyramidalization given as the sum of bond angles / ${ }^{\circ}$ in the amino groups

\begin{tabular}{ccc}
\hline Atom & $\mathbf{2}$ at $295 \mathrm{~K}$ & $\mathbf{2}$ at $150 \mathrm{~K}$ \\
\hline N11 & $337(1)$ & $337(1)$ \\
N12 & $353(1)$ & $351(1)$ \\
N21 & $334(1)$ & $340(1)$ \\
N22 & $360(1)$ & $360(1)$ \\
\hline
\end{tabular}

Table 4. Selected bond distances of 2 at 295 and $150 \mathrm{~K}$

\begin{tabular}{|c|c|c|}
\hline \multirow[t]{2}{*}{ Bond } & \multicolumn{2}{|c|}{$d(\mathrm{C}-\mathrm{N}) / \AA$} \\
\hline & $295 \mathrm{~K}$ & $150 \mathrm{~K}$ \\
\hline C13-N11 & $1.4070(18)$ & $1.4149(14)$ \\
\hline C14-N12 & $1.3724(19)$ & $1.3761(15)$ \\
\hline C17-N13 & $1.3168(17)$ & $1.3201(14)$ \\
\hline C17-N14 & $1.3109(18)$ & $1.3206(14)$ \\
\hline C23-N21 & $1.4135(18)$ & $1.4169(15)$ \\
\hline $\mathrm{C} 24-\mathrm{N} 22$ & $1.373(2)$ & $1.3708(17)$ \\
\hline C27-N23 & $1.303(2)$ & $1.3129(16)$ \\
\hline C27-N24 & $1.309(2)$ & $1.3252(18)$ \\
\hline
\end{tabular}

thus correlating with the degree of pyramidalization (Table 3). The two shorter hydrogen bonds N13H13B $\cdots \mathrm{N} 21(1-x, 1-y,-z)$ of $2.9565(14) \AA$ and N23$\mathrm{H} 23 \mathrm{~A} \cdots \mathrm{N} 11(-x+1,-y+1)$ of $2.9654(15) \AA$ result in the highest degrees of pyramidalization: the sums of the bond angles around $\mathrm{N} 21$ and $\mathrm{N} 11$ are $340(1)^{\circ}$ and $337(1)^{\circ}$, respectively. A very weak hydrogen bond is $\mathrm{N} 24-\mathrm{H} 24 \mathrm{~B} \cdots \mathrm{N} 12(x+1, y, z)$ of 3.314(2) A resulting in a flat pyramid with the sum of the bond angles being $351(1)^{\circ}$. There is no hydrogen bond toward N22 and the group is planar: resonance wins here. These results are also in correlation with the $\mathrm{C}-\mathrm{N}$ (amino group) bond lengths, those involving N21 and N11 are significantly longer than those involving N12 and N22 (Table 4).

We were interested to see if this effect can be seen in the structures deposited in the Cambridge Structural Database. At first it was searched for a benzene ring with an amino group and analyzed for pyrimidalization in dependence of the $\mathrm{N}-\mathrm{H} \cdots \mathrm{N}$ hydrogen bond with the amino group being the acceptor. No restrictions were made regarding other substituents. The search was for high quality structures without disorders and errors. No metals were allowed and the $R$ factor was restricted to be less than $5 \%$. The hydrogen bond angle was set to be greater than $120^{\circ}$. Hits with structures having a difference in the two $\mathrm{N}-\mathrm{H}$ bond lengths greater that $0.2 \AA$ were suppressed. The results were interesting, showing that almost all amino groups that were acceptors of a hydrogen bond had some degree of pyramidalization (Figure 3). The exceptions were amino groups that were constrained to be planar, for example structures with refcodes DUPCAT ${ }^{26}$ and IJUZET, ${ }^{27}$ the two bottom hits at the $360^{\circ}$ line in Figure 3. In the structure of $N^{4}-(3-$ bromophenyl)quinazoline-4,6-diamine (DUPCAT) the authors reported that the $\mathrm{H}$ atoms of the amino group were located in a difference map and refined freely which is not supported by two same $\mathrm{N}-\mathrm{H}$ bonds without s.u. and all angles of $120^{\circ}$ in one of the two independent molecules. Similarly, in $N, N^{\prime}$-bis(4-aminobenzyl)oxalamide (IJUZET) the two amino groups are planar. This approximation might not present a great error since the 


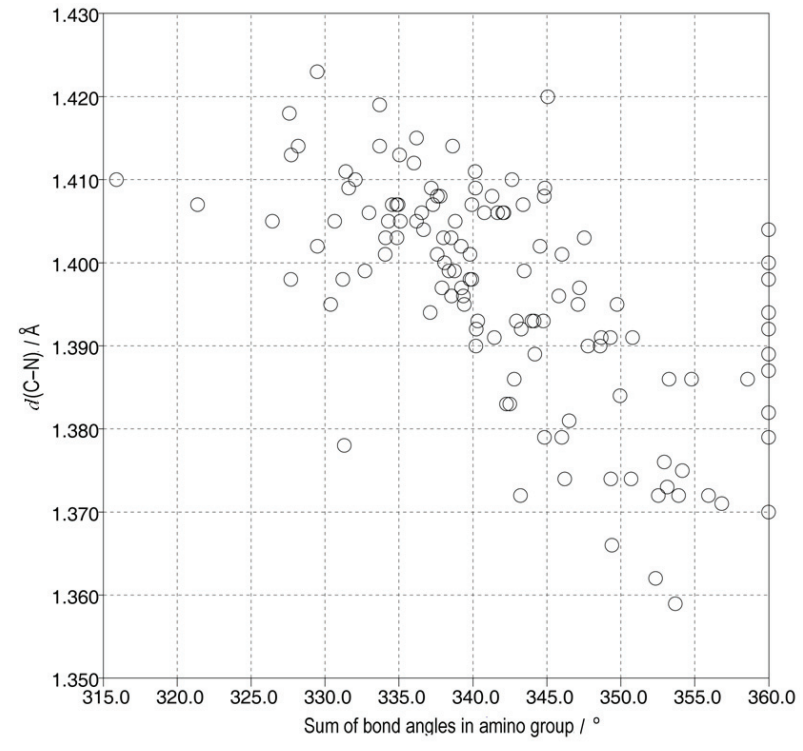

Figure 4. Scatter plot of 127 hits from the CSD illustrating the relation of the sum of the bond angles $\left(^{\circ}\right)$ in the amino group and the $\mathrm{C}-\mathrm{N}$ (amino group) bond distance $(\AA)$.

hydrogen bonds to these amino groups are weak. On contrary, in the structure of 4,4'-diaminobenzophenone $(\mathrm{AMBZPH})^{28}$ the amino group is pyramidal although this group is not an acceptor of a hydrogen bond and should therefore be planar.

Much better correlation was of the amino group $\mathrm{C}-\mathrm{N}$ bond length with pyramidalization: the resonance effect influences a shorter bond length when the group is less pyramidalized (Figure 4) as a consequence of the expected change in hybridization at the nitrogen atom. This is consistent with the increased double bond character and with the shorter $\mathrm{C}-\mathrm{N}\left(\mathrm{sp}^{2}\right)$ bond length in comparison with the $\mathrm{C}-\mathrm{N}\left(\mathrm{sp}^{3}\right){ }^{29}$

Overall, in this CSD search the tested structures had too many differences in substituents to give any other conclusion on the dependence of pyramidalization on the length of the hydrogen bond. Somewhat better correlation was obtained $\left(N=57, R_{\text {corr }}=0.648\right)$ when an additional restriction was added: no substituents in the ortho position to the amino group (Figure 5). Linear regression is given in this scatter plot.

Multiple hydrogen bonds to the same amino group additionally complicate this analysis as can be seen in the structure of hexaaminobenzene ${ }^{16}$ where the molecule has six identical amino groups and there are two very weak hydrogen bonds toward the amino nitrogen atom of 3.323(8) and 3.332(8) $\AA$ resulting in a significantly pyramidalized amino group $\left(338(5)^{\circ}\right)$ and a long $\mathrm{C}-\mathrm{N}$ bond length of 1.432(8) $\AA$. Quite different is the case of 4-amino- $N$-isopropylbenzamidinium chloride ethanol solvate ${ }^{30}$ where there are no hydrogen bonds toward the amino group, there is no pyramidalization and the $\mathrm{C}-\mathrm{N}$ bond is short, 1.365(2) $\AA$.

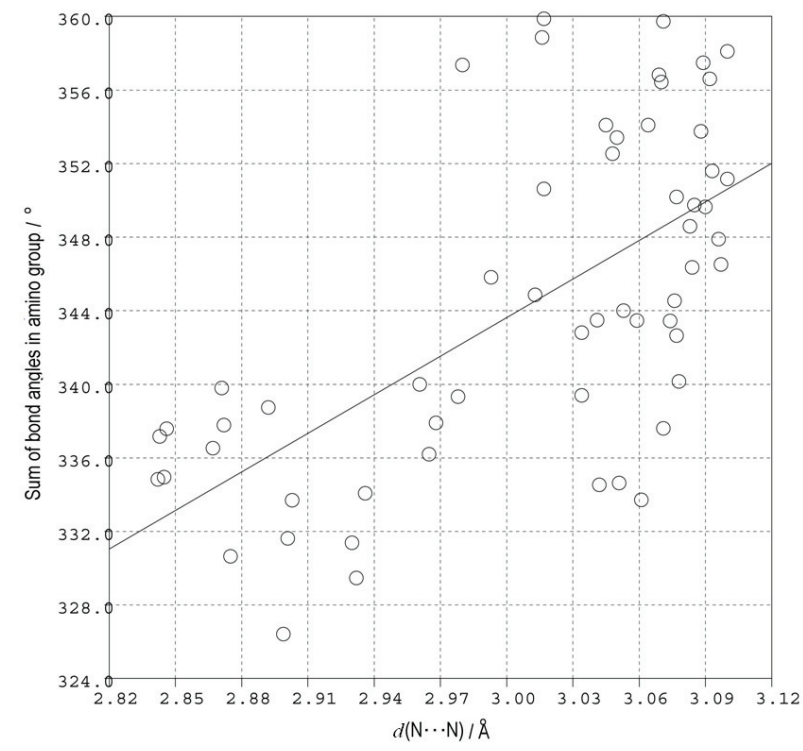

Figure 5. Scatter plot of 57 hits from the CSD and the linear regression plot illustrating correlation of the sum of the bond angles in the amino group and the $\mathrm{N} \cdots \mathrm{N}$ distance in the $\mathrm{N}-\mathrm{H} \cdots \mathrm{N}$ (amino group) hydrogen bond.

\section{CONCLUSION}

4-amino-3-nitrobenzamidinium chloride and 3,4-diaminobenzamidinium chloride were synthesized and spectroscopically characterized. X-ray structure analysis of 3,4diaminobenzamidinium chloride revealed a large network of hydrogen bonds in the crystal structure. It was found that the amino groups that are acceptors of hydrogen bonds are pyramidalized. An analysis of the influence of hydrogen bonds upon pyramidalization of the amino group attached to a benzene ring in the structures deposited in the Cambridge Structural Database was made. Correlation of the hydrogen bond length with pyramidalization of the amino group was found. Even better correlation was of the amino group $\mathrm{C}-\mathrm{N}$ bond length with pyramidalization. However, modeling pyramidalization in an amino group when hydrogen atoms can not be found in the crystal structure should be done with caution since influence of other substituents or intermolecular interactions can not be ruled out.

Supplementary Materials. - The crystallographic data are deposited with the Cambridge Crystallographic Data Center as supplementary material with the deposition numbers: CCDC 904590 for $\mathbf{2}$ at room temperature and CCDC 904591 for $\mathbf{2}$ at $150 \mathrm{~K}$. Copies of the data can be obtained free of charge via http:/www.ccdc.cam.ac.uk/const/retrieving.html. The IR spectra can be obtained from the authors.

Acknowledgements. This work was supported by the Ministry of Science, Education and Sports of the Republic of Croatia (Grant Nos. 119-1193079-1084 and 053-0982914-2965). Mr. 
Boris Zimmermann's help in FT-IR measurements is gratefully acknowledged.

\section{REFERENCES}

1. C. J. Suckling, Expert Opin. Ther. Patents 14 (2004) 1693-1724.

2. M. Del Poeta, W. A. Schell, C. C. Dykstra, S. Jones, R. R. Tidwell, A. Czarny, M. Bajić, Ma. Bajić, A. Kumar, D. W. Boykin, and J. R. Perfect, Antimicrob. Agents Chemother. 42 (1998) 2495-2502.

3. L. Hu, M. L. Kully, D. W. Boykin, and N. Abood, Bioorg. Med. Chem. Lett. 19 (2009) 1292-1295.

4. M. Alp, H. Göker, R. Brun, and S. Yildiz, Eur. J. Med. Chem. 44 (2009) 2002-2008.

5. K. Gillingwater, A. Kumar, M. A. Ismail, R. K. Arafa, C. E. Stephens, D. W. Boykin, R. R. Tidwell, and R. Brun, Vet. Parasitol. 169 (2010) 264-272.

6. G. Xiao, A. Kumar, K. Li, C. T. Rigl, M. Bajić, T. M. Davis, D. W. Boykin, and W. D. Wilson, Bioorg. Med. Chem. 9 (2001) 1097-1113.

7. M. D. Givens, C. C. Dykstra, K. V. Brock, D. A. Stringfellow, A. Kumar, C. E. Stephens, H. Goker, and D. W. Boykin, Antimicrob. Agents Chemother. 47 (2003) 2223-2230.

8. A. Lansiaux, L. Dassonneville, M. Facompre, A. Kumar, C. E. Stephens, M. Bajić, F. Tanious, W. D. Wilson, D. W. Boykin, and C. Bailly, J. Med. Chem. 45 (2002) 1994-2002.

9. A. Seaton, C. Higgins, J. Mann, A. Baron, C. Bailly, S. Neidle, and H. van den Berg, Eur. J. Cancer 39 (2003) 2548-2555.

10. I. Stolić, K. Mišković, A. Magdaleno, A. M. Silber, I. Piantanida, M. Bajić, and Lj. Glavaš-Obrovac, Bioorg. Med. Chem. 17 (2009) 2544-2554.

11. K. T. Hopkins, W. D. Wilson, B. C. Bender, D. R. McCurdy, J. E. Hall, R. R. Tidwell, A. Kumar, M. Bajić, and D. W. Boykin, J. Med. Chem. 41 (1998) 3872-3878.

12. M. A. Weidner-Well, K. A. Ohemeng, V. N. Nguyen, S. FragaSpano, M. J. Macielag, H. M. Werblood, B. D. Foleno, G. C. Webb, J. F. Barrett, and D. J. Hlasta, Bioorg. Med. Chem. Lett. 11 (2001) 1545-1548.
13. S. Ozbey, F. B. Kaynak, C. Kus, and H. Göker, Acta Crystallogr. E58 (2002) 1062-1064.

14. K. Bahrami, M. M. Khodaei, and F. Naali, J. Org. Chem. 73 (2008) 6835-6837.

15. J. Mann, A. Baron, Y. Opoku-Boahen, E. Johansson, G. Parkinson, L. R. Kelland, and S. Neidle, J. Med. Chem. 44 (2001) 138-144.

16. D. A. Dixon, J. C. Calabrese, and J. S. Miller, Angew. Chem. Int. Ed. 28 (1989) 90-92.

17. I. V. Alabugin, M. Manoharan, M. Buck, and R. J. Clark, J. Mol. Struct: THEOCHEM 813 (2007) 21-27. For older references regarding theoretical calculation of pyramidalization see references therein.

18. F. H. Allen, Acta Crystallogr. B58 (2002) 380-388.

19. CrysAlis PRO, Oxford Diffraction Ltd., Version 1.171.33.66 (2010).

20. G. M. Sheldrick, Acta Crystallogr. A64 (2008) 112-122.

21. A. L. Spek, J. Appl. Crystallogr. 36 (2003) 7-13.

22. C. F. Macrae, P. R. Edgington, P. McCabe, E. Pidcock, G. P. Shields, R. Taylor, M. Towler, and J. van de Streek, J. Appl. Crystallogr. 39 (2006) 453-457.

23. T. A Fairley, R. R. Tidwell, I. Donkor, N. A. Naiman, K. A. Ohemeng, R. J. Lombardy, J. A. Bentley, and M. Cory, J. Med. Chem. 36 (1993) 1746-1753.

24. V. G. Thailambal, V. Pattabhi, and T. N. Guru Row, Acta Crystallogr. C42 (1986) 587-589.

25. D. Matković-Čalogović, Z. Popović, V. Tralić-Kulenović, L. Racanè, and G. Karminski-Zamola, Acta Crystallogr. C59 (2003) o190-o191.

26. D.-L. Li, Y. Wu, Q. Wang, G. He, and L.-T. Yu, Acta Crystallogr. E66 (2010) o447.

27. J. S. Gonzalez-Gonzalez, F. J. Martínez-Martínez, E. V. GarcíaBáez, O. M. Franco-Hernández, and I. I. Padilla-Martínez, Acta Crystallogr. E67 (2011) o398.

28. G. P. M vander Velden, and J. H. Noordik, J. Cryst. Mol. Struct. 10 (1980) 83-92.

29. I. V. Alabugin and M. Manoharan, J. Comput. Chem. 28 (2007) 373-390.

30. I. Jarak, G. Karminski-Zamola, G. Pavlović, and Z. Popović, Acta Crystallogr. C61 (2005) o98-o100. 